\title{
Fleksible endoskop ile özofagustan yassı pil çıkarılması
}

\section{Removing a swallowed button battery from the esophagus with a flexible endoscope}

\author{
Hüseyin Sancar BOZKURT \\ Özel Tarsus Medikal Park Hastanesi, Gastroenteroloji Bölümü, Tarsus, Içel
}

\section{Sayın editör;}

Çocuklarda yabancı cisim yutma oldukça sık görülmektedir. Vakaların \%80'i 6 ay ila 3 yaş arasındadır $(1,2)$. Yassı pil en az karşılaşılan yutulan cisim olup, özofagusta kalma yüzdesi çok düşük olmasına rağmen saatler içinde şiddetli hasar ve ölümcül sonuçlara yol açabilmektedir $(3,4)$. 3 yaşında erkek hasta tartı pili yutmasindan 2 saat sonra hipersalivasyon, kusma ve göğüste yanma şikayeti ile kliniğimize başvurdu. Çekilen direk grafide (Resim 1) özofagus orta kısıma uyan bölgede pil görünümü olan hastaya acil genel anestezi eşliğinde fleksible endoskopi uygulandı. Özofagus 20.cm'de ileri derecede termal, korozif özofagus hasarı ile birlikte yassı, düz yüzeyli pil görünümü izlendi. Pil, pelikan dişlisi yardımı ile sorunsuz çıkarıldı (Resim 2). Pilin çapı $23 \mathrm{~mm}$ ve lityum özellikte idi. Tamamlanan panendoskopide özofagus $20 . \mathrm{cm}$ ile 25. $\mathrm{cm}$ arasinda ileri derece termal korozif özofajit izlendi. Çocuk cerrahisi kliniğine yatırılan hastaya medikal tedavi verildi. 2. gün çekilen direk grafide ve hastanın kliniğinde göğüs ağrısı, mediastenit, perforasyon gibi komplikasyon izlenmedi. 3. günde hasta şifa ile taburcu edildi. Özofagusta kalma süresi 2 saati geçen ve $>20 \mathrm{~mm}$ çapında olan yassı pil yutma vakalarında yüksek mortalite ve komplikasyonlar bildirilmiştir (5). Acil yapılan fleksible endoskopide standart yakalama forsepsleri yerine pelikan dişlinin kullanılması işlem başarısını artırabilir.

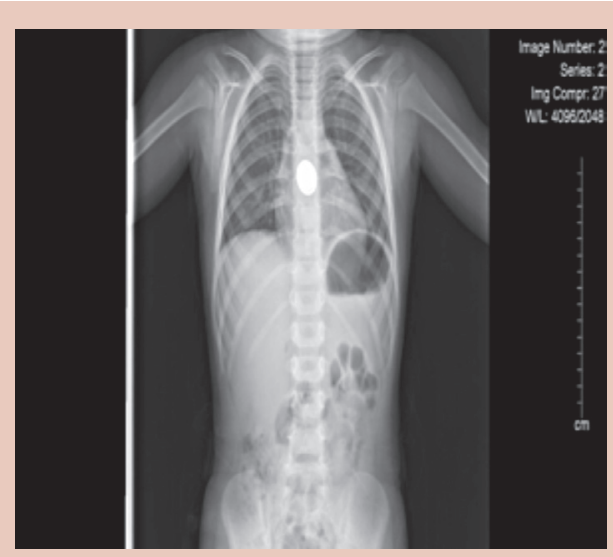

Resim 1. Pil yutumundan sonraki 2. saatte çekilen direk grafi.
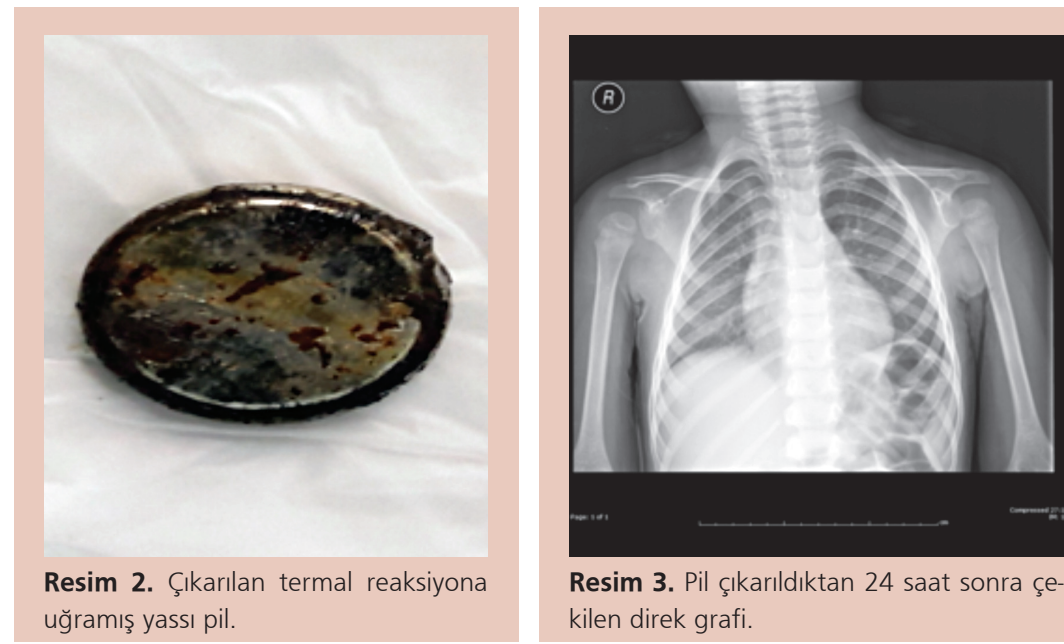

Resim 3. Pil çıkarıldıktan 24 saat sonra çekilen direk grafi.

\section{KAYNAKLAR}

1. Wyllie R. Foreign bodies in the gastrointestinal tract. Curr Opin Pediatr 2006;18:563-4.

2. Uyemura MC. Foreign body ingestion in children. Am Fam Physician 2005; 72:287-91.

3. Cheng W, Tam PK. Foreign-body ingestion in children: Experience with 1265 cases. J Pediatr Surg 1999;34:1472-6.
4. Litovitz T, Whitaker N, Clark L, et al. Emerging battery-ingestion hazard: Clinical implications. Pediatrics 2010;125:1168-77.

5. Kimball SJ, Park AH, Rollins MD 2nd, et al. A review of esophageal disc battery ingestions and a protocol for management. Arch Otolaryngol Head Neck Surg 2010;136:866-71. 